\title{
BMJ Open Management and Point-of-Care for Tobacco Dependence (PROMPT): a feasibility mixed methods community- based participatory action research project in Ottawa, Canada
}

\author{
Smita Pakhale, ${ }^{1,2,3}$ Tina Kaur, ${ }^{2}$ Catherine Charron, ${ }^{1,3}$ Kelly Florence, ${ }^{4}$ Tiffany Rose, ${ }^{4}$ \\ Sadia Jama, ${ }^{2}$ Robert Boyd, ${ }^{5}$ Joanne Haddad, ${ }^{6}$ Gonzalo Alvarez, ${ }^{1,2,3}$ Mark Tyndall ${ }^{7,8}$
}

To cite: Pakhale S, Kaur T, Charron C, et al. Management and Point-of-Care for Tobacco Dependence (PROMPT): a feasibility mixed methods community-based participatory action research project in Ottawa, Canada. BMJ Open 2018;8:e018416. doi:10.1136/ bmjopen-2017-018416

- Prepublication history and additional material for this paper are available online. To view these files, please visit the journal online (http://dx.doi. org/10.1136/bmjopen-2017018416).

Received 28 June 2017 Revised 21 November 2017 Accepted 22 November 2017

Check for updates

${ }^{1}$ Ottawa Hospital, Ottawa, Ontario, Canada

${ }^{2}$ Ottawa Hospital Research Institute, Ottawa, Ontario,

Canada

${ }^{3}$ University of Ottawa, Ottawa, Ontario, Canada

${ }^{4}$ The Bridge Engagement Centre, Ottawa, Ontario, Canada

${ }^{5}$ Oasis, Sandy Hill Community Health Centre, Ottawa, Ontario, Canada

${ }^{6}$ Canadian Mental Health Association, Ottawa, Ontario, Canada

${ }^{7}$ British Columbia Centre for Disease Control, Vancouver,

Canada

${ }^{8}$ University of British Columbia, Vancouver, Canada

Correspondence to

Dr Smita Pakhale;

spakhale@ohri.ca

\section{ABSTRACT}

Objective To determine the feasibility of a CommunityBased Participatory Tobacco Dependence Strategy (PROMPT) in the inner city population of Ottawa (Canada). Design A feasibility mixed methods prospective cohort study following principles of community-based participatory action research.

Intervention Recruited 80 people whouse drugs, followed them for 6 months while providing access to counselling, nicotine replacement therapy and peer-support in a community setting.

Setting Community research office in downtown Ottawa, adjacent to low-income housing, shelter services and street-based drug consumption.

Primary outcome Retention rate at 6-month follow-up. Secondary outcome Biochemically validated 7-day point prevalence smoking abstinence at 26 weeks, self-reported abstinence in the past 7 days with exhaled carbon monoxide $\leq 10 \mathrm{ppm}$.

Results The average age of participants was 43.8 years. The 6 -month follow-up rate was $42.5 \%$. The mean number of smoking years reported was 27.3 years. The participants were $70 \%$ male, $33.7 \%$ reported less than a high-school education, $21 \%$ identified as indigenous and $43.8 \%$ reported an income between US\$1000 and US $\$ 1999$ per month. The baseline mean daily cigarette use was 20.5 and 9.3 cigarettes at study end, with mean reduction of 11.2 cigarettes at 6 months ( $P=0.0001)$. There was a considerable reduction in self-reported illicit substance use (18.8\%), including a reduction in the opioids heroin (6.3\%), fentanyl $(2.6 \%)$ and 0xycontin (3.8\%). The study findings also reveal psycho-socioeconomic benefits such as improved health, return to work and greater community engagement.

Conclusions The PROMPT project describes socioeconomic variables associated with tobacco and polysubstance use. A programme focused on tobacco dependence, easily accessible in the community and led by community peers with lived experience is feasible to implement and has the potential to support positive life changes. PROMPT's patient engagement model is an effective harm-reduction strategy for the growing opioid use crisis and can improve the health outcomes of marginalised at-risk populations worldwide.

\section{Strengths and limitations of this study}

- Prospectively engaged a highly marginalised hardto-reach low-income population.

- Biochemical validation and self-report of smoking abstinence.

- Equitable care through a community-based participatory action research model.

- One setting with a similar profile as inner cities across Canada and the USA.

- Feasibility study with a small sample size.

\section{INTRODUCTION}

Tobacco smoking is a leading preventable cause of morbidity and mortality in Canada and around the world. ${ }^{1}$ The effects of nicotine, the pharmacologically active agent in tobacco products, is acutely toxic as nicotine readily enters the body through the lungs and is distributed rapidly throughout the bloodstream. ${ }^{1}$ Beyond the addictive properties of nicotine, it activates multiple biologic pathways that play a role in hampering fetal growth and development, the immune system, the cardiovascular system and the central nervous system, in addition to stimulating carcinogenesis. ${ }^{1}$ The life expectancy of tobacco smokers is cut short as smoking is documented to shorten life far more than most other risk factors for premature death; smokers are estimated to lose more than a decade of life in comparison to non-smokers. ${ }^{1}$ Despite a steady decline in cigarette smoking since 1964, large disparities in rates of tobacco use remain evident across groups defined by race, ethnicity, education level and socioeconomic status (SES) and across regions in all high-income countries including Canada. ${ }^{1-3}$ Major health disparities exist between smokers and non-smokers 
and are evident with lower socioeconomic status groups having disproportionately higher rates of tobacco use. ${ }^{4}$ Globally, disadvantaged groups between the ages of 35 and 69 years are much more likely to die from tobacco smoking. ${ }^{35}$ Tobacco is responsible for about half of the socioeconomic difference in death rates for this age range. ${ }^{36}$ Specifically, smoking tobacco rates are higher among the long-term unemployed, homeless or at-risk for homelessness, mentally ill, prisoners, single parents, people with limited education, people with low income and some groups of immigrants and ethnic minorities, ${ }^{37}$ which are more likely to be socioeconomically disadvantaged. ${ }^{38-11}$

Polysubstance use and tobacco use are common co-occurrences in homeless or at-risk for homelessness populations in North America. ${ }^{12}$ Although the city of Ottawa (Canada) has one of the lowest smoking rates in the Province of Ontario $(9 \%-12 \%),{ }^{13} 14$ major disparities exist as disproportionately higher rates of tobacco smoking were observed among people who use drugs (PWUD). According to the PROUD (Participatory Research in Ottawa: Understanding Drugs) study of Ottawa inner city residents who use multiple drugs, $96 \%$ of respondents reported they had smoked cigarettes in the past year. ${ }^{14} 15$ Furthermore, similar trends are observed in the USA, for example, $29 \%$ of the general population smoked in comparison to $75 \%-100 \%$ for people who abuse alcohol, PWUD and those receiving methadone maintenance. Many people recovering from polysubstance addictions die from smoking-related illnesses. ${ }^{16} 17$

Reducing the harm associated with cigarette smoking among lower SES groups creates opportunities for improving the health and well-being of disadvantaged communities, in addition to reducing the disproportionate burden of smoking-related illness on the healthcare system. ${ }^{10}{ }^{18} \mathrm{~A}$ harm reduction paradigm emphasises a pragmatic approach to substance use, removing moral judgement, and instead prioritising health problems associated with substance abuse in order to reduce and minimise individual and societal consequences. ${ }^{19}$ Moreover, a harm reduction approach acknowledges that many substance users may never achieve (or even have the desire to achieve) abstinence and that in light of this reality it is important to provide non-abstinence-based alternatives to reduce exposure to risk and harm from substance misuse. ${ }^{19}$ The success of harm reduction among illicit drug users carries over to tobacco harm reduction efforts, which in addition to a reduction in smoking also includes the use of nicotine replacement therapy (NRT) (eg, nicotine patch, gum, inhaler, etc). Among alternative nicotine products, NRTs are the least harmful with a marked reduction in cardiovascular disease and negligible carcinogenic risk or risk for acquiring respiratory disease. $^{20}$

Mental illness is strongly associated with the initiation and maintenance of cigarette smoking. ${ }^{21}$ Individuals with mental health issues smoke tobacco at an alarmingly high rate, and as a result experience an increased risk for smoking-related illnesses. Smokers with mental health issues often start smoking at a younger age, are heavy smokers and are less likely to participate and succeed in smoking reduction and cessation efforts. In particular, smoking is highly prevalent among individuals with anxiety and/or depression, who are more likely than individuals with other mental health issues to experience failed cessation attempts and relapse postcessation. ${ }^{21}$ Some studies propose a self-medication theory where individuals with mental health issues use substances to cope with their mental illness, while other studies suggest that smoking may act as a catalyst for the development of mental health issues. The opposite is also true as there is evidence that a reduction or cessation of smoking behaviour can improve the physical and mental health-related quality of life (QOL) of smokers. One study in particular demonstrated a reduction in panic disorder and agoraphobia among quitters $^{21}$; and another demonstrated that smokers were more likely to report poor physical and mental health-related QOL when compared with non-smokers and former smokers. $^{22}$

Despite well-established benefits of tobacco harm reduction and smoking cessation, ${ }^{123}$ common misconceptions exist when treating PWUD, for example, that smoking cessation will interfere with drug dependence treatment by becoming an additional stressor. Healthcare providers may bring in their own biases and feel that smoking tobacco is not a priority issue in comparison to other substance use. ${ }^{16}$ Yet, research shows that $44 \%-80 \%$ of PWUD are interested in quitting tobacco, $72 \%$ of PWUD reported trying to quit tobacco smoking and $69 \%$ expressed interest in participating in a group smoking cessation programme. Moreover, $82 \%$ of PWUD indicated interest in receiving a prescription for nicotine replacement medication, and among those who considered cessation, approximately $56 \%$ reported being interested in both group intervention and nicotine replacement. ${ }^{2324}$ Therefore, the motivation to quit smoking tobacco exists within the PWUD community; however, there is a lack of programmes designed to cater to at-risk, drug using, street-based individuals. Very few research studies have followed polysubstance users and tracked their smoking activity as well as smoking cessation efforts. Importantly, with the growing crises of opioid use in the USA and Canada, novel strategies to deal with the synchronicity of coaddictions are urgently needed. ${ }^{25-27}$ Consequently, a community-based participatory action research project was conducted in the inner city population of Ottawa with PWUD. ${ }^{14}$ The purpose of the project was to assess the feasibility of implementing a community-based participatory tobacco dependence strategy in Ottawa's inner city. Feasibility centred outcomes include the impact of the project on the tobacco and polysubstance use of participants, the levels of loss to follow-up in a project that recruits active drug users and the role of peer researchers in the implementation of the project and in the smoking cessation efforts of participants. Ultimately, the PROMPT project aims to demonstrate that a 
programme focused on tobacco dependence available in the community with meaningful 'patient engagement' of community members representative of the target population is feasible and able to improve quality of life (QOL) and reduce tobacco use.

\section{METHODS}

\section{Study design and participants}

The Participatory Research in Ottawa: Management and Point-of-Care for Tobacco Dependence (PROMPT) project was a feasibility mixed methods prospective cohort study with PWUD using a community-based participatory action model. The study inclusion criteria were: (1) currently living in Ottawa for at least 3 months prior to enrolment, (2) 16 years or older, (3) have used drugs in the past year (excluding marijuana and alcohol) and (4) have smoked tobacco in the past 7 days. The exclusion criteria included: (1) consent declined (refusal from participant or decision maker); (2) any person accessing addictions treatment (in-patient drug rehabilitation) and hence unavailable for follow-up; (3) any person currently or recently (in the past 30 days) enrolled in a smoking cessation programme and (4) anyone with a terminal illness with a life expectancy of $<3$ months. Written informed consent was obtained from all participants.

Four individuals with lived experience, members of the PROMPT target population (ex/current tobacco smoker, homeless or at-risk for homelessness, polysubstance user), were selected as community (peer) researchers. The community researchers were selected through a low-threshold, inclusive and informal interview process. The informal interviews were conducted at the project site with community members. Prospective candidates were assessed for their passion and interest in community well-being; prior experience in similar community-based projects was optional. A partnership between community researchers and academics was formed and regular meetings were held throughout the project. All members of the team (including community researchers) participated in the design of the project and questionnaires, including item development, development of strategies for recruitment and retention using a social network approach, data entry, data cleaning, data analysis, preparation of posters/abstracts/handouts and manuscript preparation and knowledge mobilisation. The patient engagement approach used in the PROMPT project, 'The Ottawa Citizen Engagement and Action Model', is described in detail in another publication. ${ }^{14}$

The community researchers underwent intensive training prior to participant enrolment. The training focused on privacy, confidentiality, Tri-Council Policy Statement: Ethical Conduct for Research Involving Humans, harm reduction, the role of peer interviewers, interviewing skills, obtaining study consent from participants, administering surveys with iPads and administering lung function testing and certification for hand-held spirometry and oscillometry. After the training, community researchers created a list of project requirements that they posted in participant interview rooms as an added measure to adhere to the project's protocol and procedures. Community researchers were given an honorarium (CAD $\$ 15 /$ hour) for the time spent conducting project-related activities such as trainings, meetings, consenting, follow-ups, social networking for recruitment and retention, knowledge mobilisation and data cleaning and analysis. Throughout the life of the project, community researchers also navigated their social networks to encourage participants to attend life-skills workshops, nurse counselling and monthly follow-up appointments.

\section{Study procedure}

The structure of the recruitment strategy, interviewing and point-of-care testing, closely followed the principles of community-based participatory action research. As pairs, community researchers conducted street-based recruitment 5 days a week assessing eligibility and providing appointment times for enrolment, either on the same day or as per the potential participants' convenience. Coercion for participation was avoided by pairing of community researchers and through rigorous ethics training. At the baseline visit community researchers acquired consent, administered iPad-based baseline questionnaires, two point-of-care lung function tests, hand-held spirometry and oscillometry. The consent process was conducted at the community research office. Community researchers also administered a monthly iPad-based follow-up survey for 6 months ending with the administration of hand-held spirometry and oscillometry at the last follow-up. Participants were given CAD $\$ 20$ at baseline enrolment and CAD $\$ 25$ at each monthly visit to compensate for their time and effort.

All participants were enrolled in the Smoking Treatment for Ontario Patients (STOP) programme led by the Centre for Addiction and Mental Health, Toronto Branch, in order to receive free and 'off-label' NRT. After providing consent to participate in the PROMPT project participants met with an expert tobacco dependence treatment nurse from the Ottawa chapter of the Canadian Mental Health Association (CMHA). The CMHA nurse was specifically hired for the PROMPT project and was available onsite twice a week to offer one-on-one counselling and individualised NRT available through the STOP programme. The participants could meet the nurse as frequently as requested by the participant or as deemed clinically necessary by the nurse. The study followed the current clinical practice of the CMHA to prescribe and dispense an amount of NRT titrated to suppress nicotine cravings. This could be referred to as 'off-label' use of NRT, because the standard prescription of NRT, especially of nicotine patches, is titrated according to the number of daily cigarettes used. The CMHA nurse provided brief counselling sessions (approximately $20 \mathrm{~min}$ ) using motivational interviewing techniques and strategies to help participants strengthen their motivation to change and reduce their dependence on nicotine. The nurse and 
academic staff also supported participants in their efforts to access housing, healthcare services and legal support by writing letters of support and connecting participants to community resources. Lastly, exhaled carbon monoxide (CO) was measured during visits with the nurse using a Bedfont Micro Smokerlyzer for biochemical confirmation of self-reported quitting.

To further involve the community, weekly peer-led life skills workshops were conducted on a variety of topics such as financial literacy, banking, peer-support, HIV/hepatitis $\mathrm{C}$ education, pet-care, cooking, mindfulness meditation and art. Community researchers took the lead in organising and conducting these workshops. Volunteers from community organisations helped facilitate some of the life-skills workshops. In addition, quarterly Community Knowledge Forums were designed and conducted by community researchers and project participants. The knowledge mobilisation forums helped disseminate project outcomes and were attended by PROMPT participants, community members, healthcare service provider allies, and occasionally by the local media, the Ottawa Police, and members of the provincial parliament. ${ }^{28}$

PROMPT project-related activities were conducted at a Community Research Centre, near Ottawa's largest homeless shelter, located downtown in Ottawa's popular ByWard market which is at the centre of open drug consumption and homelessness. A Community Advisory Committee (CAC) was formed at the centre with five voting members (PROMPT community researchers and participants) and five non-voting members from neighbourhood community healthcare agencies with balanced sex, gender, race, language and indigenous representation. Community researchers reached out to the community to interview and select CAC members. The CAC meets monthly and the members named the Centre appropriately as the Bridge Engagement Centre (the Bridge), a place to bridge gaps between different communities.

\section{Data and measures}

The participants underwent an expired CO test, spirometry and an oscillometry test at baseline and at the end of the project, 6 months after enrolment. Seven questionnaires were administered by the community researchers to all participants at baseline: (1) demographic information: detailed tobacco smoking history, drug use questionnaire and a social network questionnaire; (2) Fagerstorm Test for Nicotine Dependence $;^{29}(3)$ the BOLD core questionnaire used in the CanCOLD study, which aims to evaluate respiratory symptoms (cough, phlegm, whistling/wheezing, shortness of breath) $;^{30}{ }^{31}$ (4) Chronic Obstructive Pulmonary Disease Assessment Test: an open-access disease-specific questionnaire; $^{32}$ (5) EQ-5D-3L: a well-validated fiveitem questionnaire, which measures generic QOL; ${ }^{33}$ (6) Patient Health Questionnaire (PHQ-8): an eightitem open-access questionnaire, which is used to establish provisional depressive disorder diagnoses as well as grade depressive symptom severity ${ }^{34}$ and (7) the Generalised Anxiety Disorder (GAD) questionnaire, a sevenitem questionnaire to assess GAD. ${ }^{14-20}$ A brief follow-up questionnaire was administered by the community researchers at monthly follow-ups, pertaining to questions regarding current tobacco smoking status and the barriers and facilitators of smoking. The community researchers administered a questionnaire at 6 months to inquire about participants' overall experience in the project, including perceived changes and challenges experienced by participants' over the course of the project. All project-related materials, including the consent form were in English.

\section{Patient Health Questionnaire-8}

Substance use disorders and depression often occur simultaneously within the same individual. ${ }^{35}$ To assess the prevalence and impact for this cohort, an eightitem version of the PHQ-8 was used. The PHQ-8 consists of eight items on which the Diagnostic and Statistical Manual of Mental Disorders, 4th Edition (DSM-IV) diagnosis of depressive disorders is based. Each participant answers the eight questions with four responses (not at all to nearly every day (0-3)) assigned to each category. The scores for each item are summed to produce a total score between 0 and 24 points. A total score of $0-4$ represents no significant depressive symptoms; 5-9 mild depressive symptoms; $10-14$ moderate; $15-19$ moderately severe and 20-24 severe. ${ }^{36}$

\section{Generalised Anxiety Disorder-7}

The GAD-7 questionnaire is a self-administered one-dimensional scale to assess the presence of the symptoms of GAD as stated in the DSM-IV. The score for each of the seven items ranges from 0 (not at all) to 3 (nearly every day), with a possible total score of $0-21$. The total score may be categorised into four severity groups: 1) minimal/no anxiety $(0-4), 2)$ mild ${ }^{5-8} 3$ ) moderate ${ }^{9-13}$ or 4) severe ${ }^{14-20}$ with an optimum cut-off value for GAD at 10 points. ${ }^{37}$

\section{EQ-5D-3L}

A frequently applied general health status measure is the EuroQol questionnaire (EQ-5D-3L). The EQ-5D-3L was a brief questionnaire used to evaluate the health-related QOL of the PROMPT cohort. ${ }^{38}$ The questionnaire consists of five dimensions: mobility, self-care, usual activities, pain/discomfort and anxiety/depression, which provides a single index value for health status for each individual. ${ }^{39}$ The participants were also given a visual analogue scale (EQ-VAS) and asked to rate their health on a $20 \mathrm{~cm}$ vertical scale that ranges from 0 to 100 , with 0 representing 'the worst health you can imagine' and 100 representing 'the best health you can imagine'. ${ }^{39}$

\section{Data analyses}

The difficulty accessing the target population, the precarious nature of the target population's living situation and 
budget constraints determined the sample size. Potential confounders were included in the development of the study exclusion criteria. A retention rate of $40 \%$ with full data collection at the 6 month follow-up was considered adequate for the project to be considered feasible, a priori. As a result of the day-to-day challenges faced by the target population (eg, housing instability, high incarceration rate, food insecurity, intermittent telephone access, etc), the study investigators estimated a high loss to follow-up, and decided a retention rate of at least $40 \%$ was reasonable and in line with the literature on high dropout rates for smoking cessation projects and projects with low-income communities. ${ }^{40}{ }^{41}$ Other feasibility centred outcomes were based on monthly follow-up data, such as self-reported and biochemically validated tobacco use; the proportion of participants that participated in each follow-up and the role of peer researchers on project implementation and impact. In particular, the variables used to measure both the primary and secondary outcome include cigarette use per day and exhaled $\mathrm{CO}$ as measured by a Bedfont Micro Smokerlyzer, respectively.

The monthly follow-up questionnaire included openended questions, in order to get as much qualitative feedback as possible from participants. A thematic analysis was conducted in order to identify recurring patterns (ie, themes) in the data. The themes were determined by quantity and quality in relation to study outcomes. Saturation was achieved when variation decreased, and no new themes emerged from the data.

Statistical analyses were performed using SAS V.9.3. Descriptive statistics were computed to provide an understanding of population characteristics and distribution of the main study variables. Paired t-tests (with Bonferroni correction) were conducted to compare baseline data and monthly follow-up data ( 6 months) on tobacco smoking per day. Baseline illicit substance use was not available because the initial survey asked for drug use ever and not current use. Follow-up data collection captured current illicit substance use. We employed an intentionto-treat (ITT) analysis a priori, as we were expecting losses to follow-up.

\section{RESULTS}

\section{Quantitative results}

Between March and August 2016, the community researchers recruited, consented and completed baseline assessments on 80 participants. The baseline characteristics of the study's participants are presented in table 1 . Most participants were male $(70 \%)$, Caucasian $(77.5 \%)$ and between the ages of 41 and 50 years. Many of the participants $(31.3 \%)$ completed their high school education, some of the participants started higher education (26.3\%) and a few (5.0\%) completed college or university. A large proportion of participants had an average monthly income between $\mathrm{CAD} \$ 1000$ and $\mathrm{CAD} \$ 1999$, with many reporting some level of food insecurity as measured by the frequency in which participants experienced hunger and were unable
Table 1 Demographic characteristics $(n=80)$

\begin{tabular}{|c|c|c|c|}
\hline $\begin{array}{l}\text { Participant } \\
\text { characteristics }\end{array}$ & $\begin{array}{l}\text { Baseline } \\
\%(n=80)\end{array}$ & $\begin{array}{l}\text { Study end } \\
\%(n=34)\end{array}$ & $\begin{array}{l}\text { Loss to } \\
\text { follow-up } \\
\%(n=46)\end{array}$ \\
\hline \multicolumn{4}{|l|}{ Gender } \\
\hline Male & 70.0 & 59 & 78 \\
\hline Female & 30.0 & 41 & 22 \\
\hline \multicolumn{4}{|l|}{ Age (years) } \\
\hline $16-30$ & 14.8 & 12 & 17 \\
\hline $31-40$ & 8.7 & 6 & 11 \\
\hline $41-50$ & 44.4 & 41 & 48 \\
\hline $51-65$ & 30.9 & 41 & 24 \\
\hline NA & 1.2 & 0 & 0 \\
\hline
\end{tabular}

Ethnicity

\begin{tabular}{lrrr} 
Caucasian & 77.5 & 71 & 83 \\
First Nations & 16.3 & 20 & 15 \\
\hline Inuit & 1.2 & 0 & 2 \\
\hline Métis* & 1.2 & 3 & 0 \\
East Asian & 1.3 & 3 & 0 \\
$\quad$ Other & 2.5 & 3 & 2 \\
$\begin{array}{l}\text { Education } \\
\begin{array}{l}\text { Grade school/ } \\
\text { some high } \\
\text { school }\end{array}\end{array}$ & 33.7 & 35 & 33 \\
\hline
\end{tabular}

$\begin{array}{llll}\text { High school } & 31.3 & 32 & 31 \\ \text { graduate/ } & & & \\ \text { General } & & \\ \text { Education } & & \\ \text { Diploma } & & & \end{array}$

$\begin{array}{llll}\text { Some college } & 26.3 & 24 & 29\end{array}$

or university

$\begin{array}{llll}\text { College/ } & 5.0 & 6 & 4 \\ \text { university } & & \end{array}$

university

completed

$\begin{array}{llll}\text { None } & 1.2 & 3 & 2 \\ \text { NA } & 2.5 & 0 & 1\end{array}$

Monthly income (CAD\$)

\begin{tabular}{|c|c|c|c|}
\hline$<499$ & 11.3 & 6 & 15 \\
\hline 500-999 & 33.7 & 29 & 37 \\
\hline 1000-1999 & 43.8 & 56 & 35 \\
\hline 2000-2999 & 10.0 & 9 & 11 \\
\hline NA & 1.2 & 0 & 2 \\
\hline \multicolumn{4}{|l|}{ Food insecurity } \\
\hline Always & 15.0 & 18 & 13 \\
\hline $\begin{array}{l}\text { Most of the } \\
\text { time }\end{array}$ & 11.2 & 6 & 15 \\
\hline Occasionally & 16.3 & 12 & 20 \\
\hline
\end{tabular}

Continued 


\begin{tabular}{cccc} 
Table 1 Continued & & \\
\hline $\begin{array}{l}\text { Participant } \\
\text { characteristics }\end{array}$ & $\begin{array}{l}\text { Baseline } \\
\%(\mathbf{n}=\mathbf{8 0})\end{array}$ & $\begin{array}{l}\text { Study end } \\
\%(\mathbf{n}=\mathbf{3 4})\end{array}$ & $\begin{array}{l}\text { Loss to } \\
\text { follow-up }(\mathbf{n}=\mathbf{4 6})\end{array}$ \\
\hline Sometimes & 26.2 & 26 & 26 \\
Usually & 10.0 & 9 & 11 \\
Never & 18.8 & 29 & 11 \\
NA & 2.5 & 0 & 4 \\
\hline
\end{tabular}

* Métis are a group of peoples in Canada who trace their descent to First Nations peoples and European settlers. They represent the majority of those identifying as Métis, although smaller communities also exist in the USA. They are recognised as one of Canada's aboriginal or indigenous peoples under the Constitution Act of 1982, along with First Nations and Inuit peoples.

$\mathrm{NA}$, missing or refuse to answer.

to afford food. Lastly, the majority of participants reported English as their first language. There was no significant difference in baseline demographic data between participants who were followed to project end $(n=34)$ relative to participants lost to follow-up.

In table 2, baseline information regarding self-reported health conditions, smoking and drug use related data for project participants is provided. Most of the participants at baseline smoked between 15 and 25 cigarettes daily for a period of 21-30 years, and purchased company branded cigarettes from convenience stores. However, over half of the participants also bought contraband cigarettes from a local dealer. The majority of participants reported using crack and marijuana in their lifetime.

Online supplementary table 1 demonstrates the frequency of depressive symptoms as measured by the PHQ-8, generalised anxiety symptoms as measured by GAD-7 and the generic QOL as measured by the EQ-5D-3L VAS. Mild anxiety was estimated to be present in $30 \%$ of participants and $32.6 \%$ of participants had moderate-to-severe anxiety scores. Mild depressive symptoms were present in $20 \%$ of participants and moderate-to-severe depression symptoms were present in $15 \%$ of participants. Mean EQ-5D-3L VAS was 62.2 , with a SD of 17.

Online supplementary table 2 shows that the majority of participants accessed at least two types of NRT of the four types of NRT available in the project: the gum, lozenge, inhaler and patch. While it is expected that participants that followed to study end accessed the most NRT and visited the nurse most often-the costs associated with NRT accessed and visits to the nurse are not substantially greater than the costs incurred by participants lost to follow-up.

Online supplementary table 3 provides changes in self-reported tobacco smoking and polysubstance use over the study's 6-month follow-up period. Participants
Table 2 Baseline tobacco smoking, self-reported health conditions and polysubstance use $(\mathrm{N}=80)$

\begin{tabular}{|cccc|}
\hline $\begin{array}{l}\text { Participant } \\
\text { characteristics }\end{array}$ & $\begin{array}{c}\text { Baseline } \\
\%(\mathbf{n = 8 0})\end{array}$ & $\begin{array}{l}\text { Study end } \\
\%(\mathbf{n = 3 4 )}\end{array}$ & $\begin{array}{l}\text { Loss to } \\
\text { follow-up } \\
\%(\mathbf{n = 4 6 )}\end{array}$ \\
\hline $\begin{array}{l}\text { Number of cigarettes per day } \\
<15\end{array}$ & 32.5 & 54 & 44 \\
\hline $15-25$ & 42.5 & 7 & 17 \\
$26-35$ & 10.0 & 33 & 35 \\
\hline $36-40$ & 6.3 & 2 & 4 \\
NA & 8.7 & 4 & 0 \\
\hline
\end{tabular}

Total years of tobacco smoking

$\begin{array}{lrrr}<10 & 12.5 & 0 & 17 \\ 10-30 & 48.7 & 35 & 50 \\ 31-50 & 32.5 & 26 & 31 \\ 51-60 & 2.5 & 2 & 2 \\ \text { NA } & 3.8 & 37 & 0\end{array}$

Cigarettes purchase

$\begin{array}{llll}\text { Convenience } & 66.3 & 58 & 71\end{array}$

store

Local dealer $50.0 \quad 53 \quad 48$

Type of cigarettes

$\begin{array}{lrrr}\begin{array}{l}\text { Company } \\ \text { branded }\end{array} & 66.3 & 62 & 70 \\ \begin{array}{l}\text { Contraband } \\ \text { cigarettes }\end{array} & 55.0 & 56 & 54 \\ \begin{array}{l}\text { Money spent } \\ \text { on cigarettes }\end{array} & \text { (US\$) } & \\ <100 & 48.1 & 50 & 50 \\ 101-200 & 28.4 & 32 & 26 \\ 201-400 & 18.5 & 12 & 24 \\ 400+ & 2.5 & 6 & 0 \\ \text { NA } & 2.5 & 0 & 0\end{array}$

Previous or current drug use

\begin{tabular}{llll} 
Crack & 66.3 & 71 & 64 \\
Marijuana & 61.3 & 61 & 62 \\
Heroine & 23.8 & 21 & 27 \\
Fentanyl & 13.8 & 18 & 11 \\
Oxycontin & 12.5 & 15 & 11 \\
Self-reported conditions & & \\
Heart disease & 7.5 & 12 & 4 \\
Hypertension & 5 & 6 & 4 \\
Diabetes & 8.8 & 9 & 9 \\
Tuberculosis & 1 & 3 & 0 \\
Stroke & 5 & 9 & 2 \\
Cancer & 5 & 6 & 4 \\
Schizophrenia & 3.8 & 3 & 4 \\
\hline
\end{tabular}

Continued 


\begin{tabular}{llll}
\multicolumn{2}{l}{ Table 2 Continued } & & \\
\hline $\begin{array}{l}\text { Participant } \\
\text { characteristics }\end{array}$ & $\begin{array}{c}\text { Baseline } \\
\%(\mathbf{n}=\mathbf{8 0})\end{array}$ & $\begin{array}{l}\text { Study end } \\
\%(\mathbf{n}=\mathbf{3 4})\end{array}$ & $\begin{array}{l}\text { Loss to } \\
\text { follow-up } \\
\text { (n=46) }\end{array}$ \\
\hline \multicolumn{1}{c}{$\begin{array}{l}\text { Depression } \\
\begin{array}{l}\text { Anxiety } \\
\text { disorder }\end{array}\end{array}$} & 35 & 47 & 26 \\
$\begin{array}{l}\text { Bipolar } \\
\text { disorder }\end{array}$ & 8.8 & 32 & 26 \\
\hline Seizures & 5 & 12 & 7 \\
\hline
\end{tabular}

$\mathrm{NA}$, missing or refuse to answer.

smoked an average of 20.5 cigarettes at baseline in comparison to 9.3 cigarettes at the 6-month follow-up. A paired t-test comparing tobacco use per day at baseline with monthly follow-ups revealed an average reduction of 11.2 cigarettes $(\mathrm{P}=0.0001)$ from baseline to study end. Participants also reported reductions in illicit substance use (18.8\%) between baseline and study-end, including a reduction in the opioids heroin $(6.3 \%)$, fentanyl $(2.6 \%)$ and Oxycontin $(3.8 \%)$. Drug use data reporting was not uniform, for example, some participants reported the use of crack in dollar figures whereas others reported in grams. Community researchers helped translate the dollar figures into grams in order to harmonise data for data analysis.

Figure 1 demonstrates the frequency of participants following up at monthly follow-up visits. Community researchers mobilised their social networks to encourage attendance at follow-up visits. Feedback from participants and community researchers indicated two main reasons for loss to follow-up: lack of transportation or food during follow-ups, and loss of participants to incarceration as the target community is subject to higher rates of enforcement for petty crimes and low-level drug trafficking and are often targeted by 'drug sweeps' before key tourism seasons.

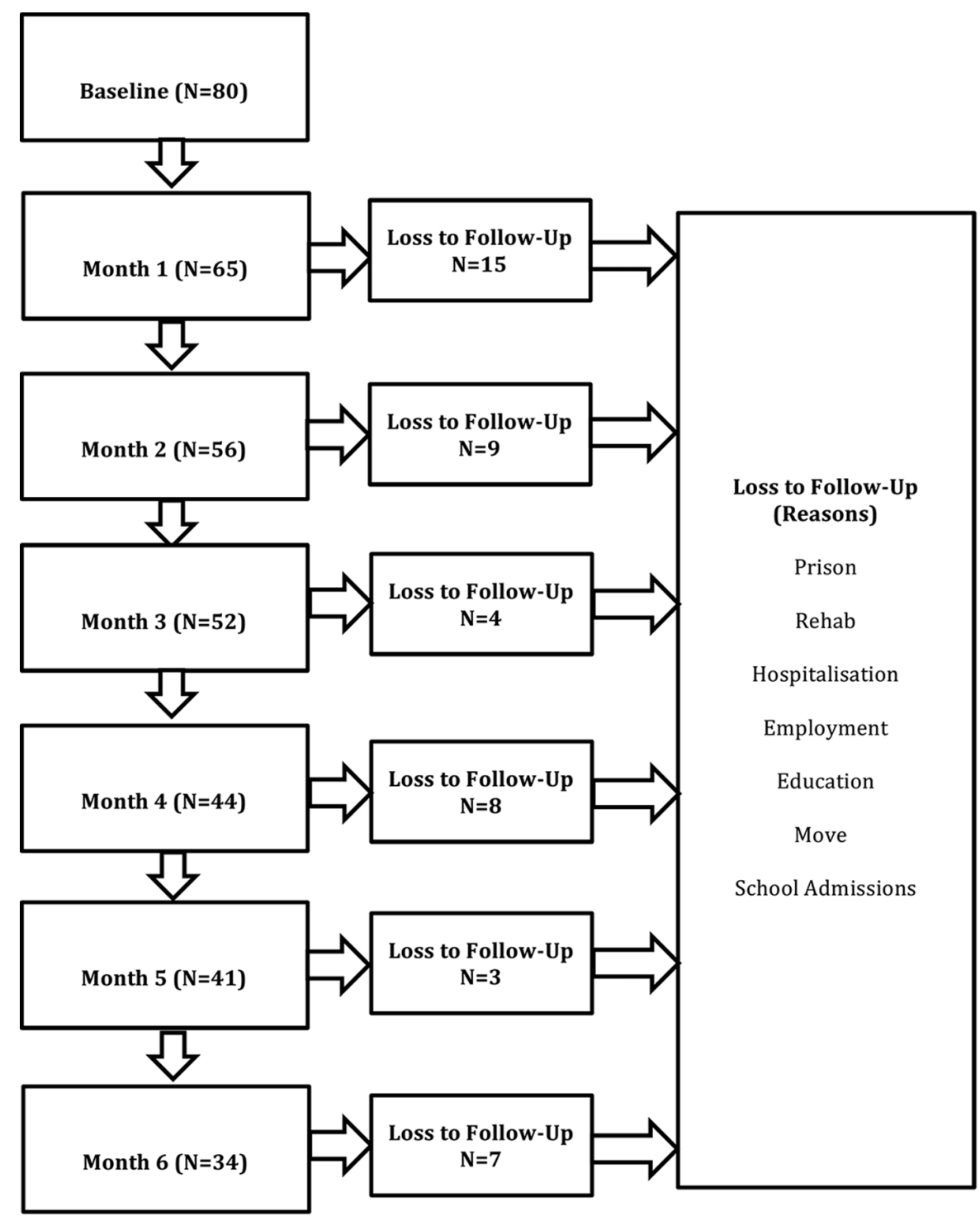

Figure 1 Frequency of participants following up monthly up to 6 months. 


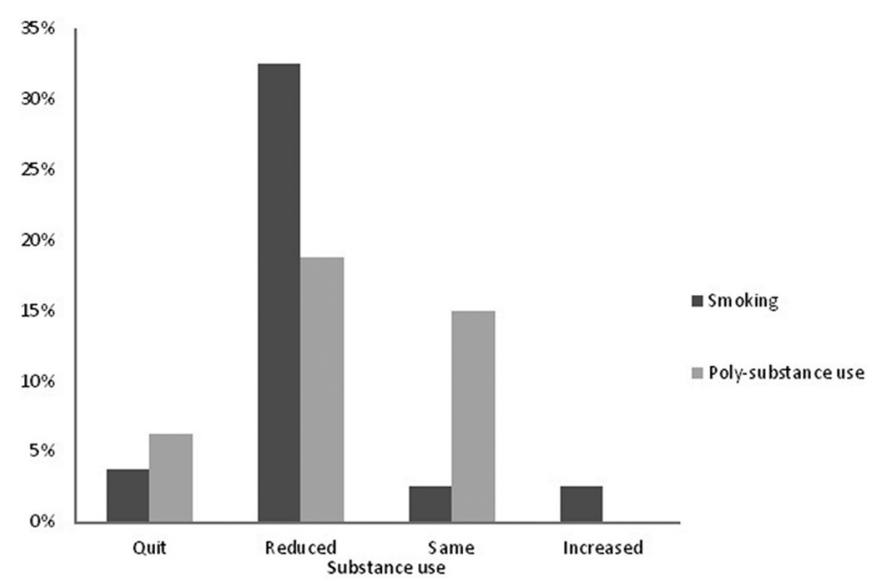

Figure 2 Polysubstance use and tobacco smoking at the 6-month follow-up visit.

Figures 2 and 3 demonstrate self-reported data from 34 participants at 6 months regarding changes in smoking and polysubstance use. The tobacco smoking quit rate was defined as biochemically validated 7-day point prevalence smoking abstinence prevalence at the 6-month follow-up visit. Reduced use for cigarettes smoking and other drug use was defined as self-reported reduction from project enrolment to the last follow-up visit. Data about tobacco use and illicit drug use was collected at monthly follow-up visits and at the final 6-month postproject survey. At around the second follow-up, the community researchers were a bit overwhelmed with the number of participants at monthly follow-up visits. The project coordinator (TK) tried to help by administering a few monthly follow-up surveys. However, the community researchers quickly observed that when the project coordinator (TK) conducted the monthly follow-up interview, the self-reported drug use was less than when they conducted the interviews. A decision was made that only community researchers would conduct the monthly follow-up interviews. Out of the total recruited participants $(\mathrm{n}=80), 32.5 \%(\mathrm{P}=0.0001)$ reported reducing their tobacco use while $18.8 \%$ reported reducing their polysubstance use, since the beginning of the programme with ITT.

Online supplementary figure 1 provides the frequency of participants who reported having problems within each dimension of EQ-5D-3L. Approximately $24.4 \%$ of the participants reported problems with mobility, $6.3 \%$ with self-care, $15.2 \%$ with usual activities, $62.0 \%$ with pain and $55.7 \%$ with anxiety. The average EQ-VAS score was 62.2 with a range of $3-100 .{ }^{35}$

Online supplementary figure 2 shows the reduction of cigarette use, paralleled by a reduction in exhaled $\mathrm{CO}$ levels measured at each participant follow-up over the full study period (11.2 cigarettes, $\mathrm{P}=0.0001$ ). Exhaled $\mathrm{CO}$ monitoring served as biochemical feedback for participants and as objective data on smoking cessation for the project.

\section{Qualitative results}

Several themes materialised from a thematic analysis of the qualitative data collected during the project's 6 -month follow-up period. The first theme that emerged was regarding the role of peer researchers and their impact on participant outcome. Many of the participants believed their progress was due to the support they received from the project's peer researchers. The peer researchers' leadership and coordination of monthly follow-ups, outreach and project-related workshops helped create a sense of community and connection that many participants report helped them manage their concurrent addictions.

When asked what helped them reduce or quit, many of the participants mentioned the study's community researchers:

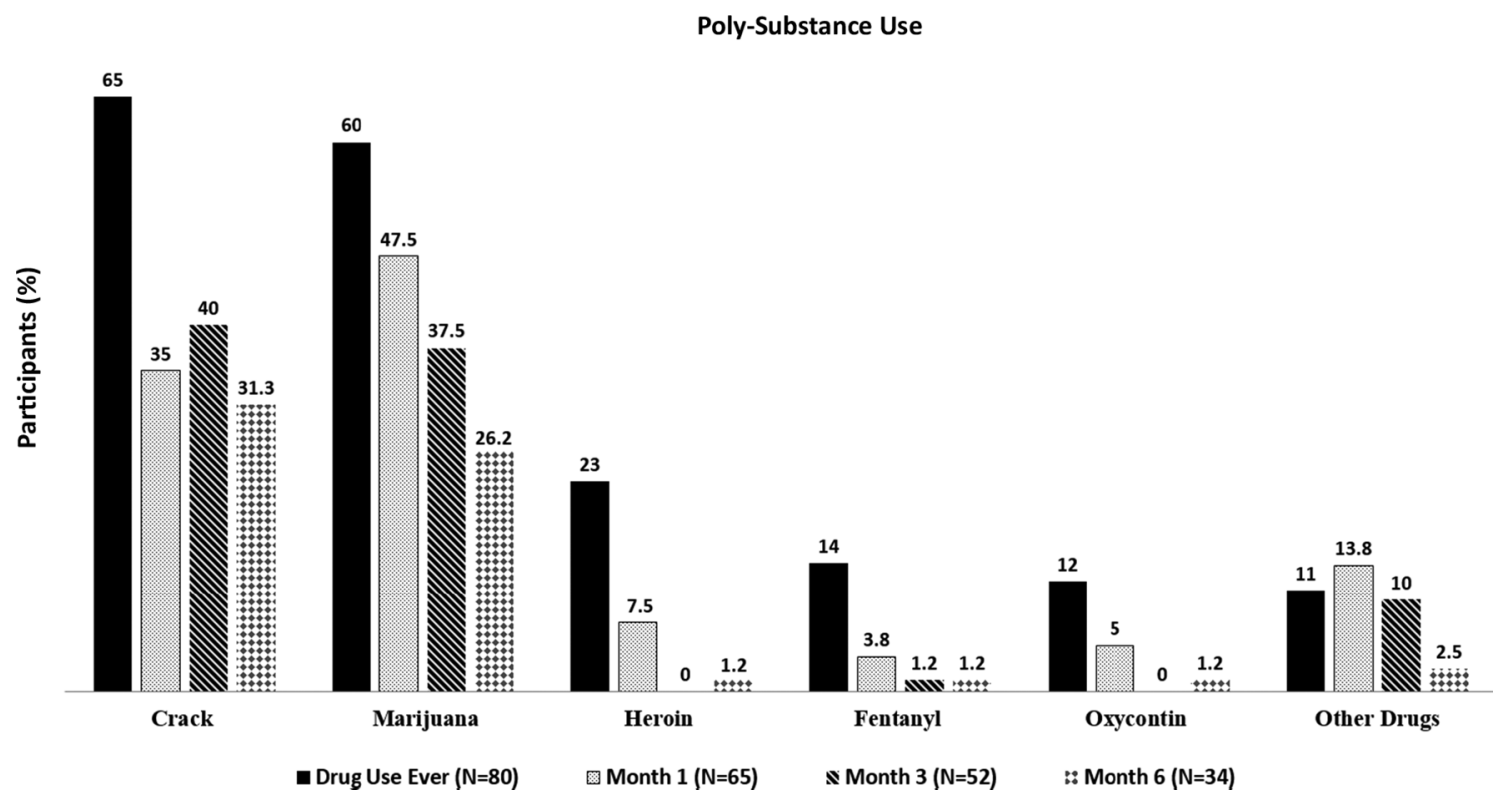

Figure 3 Polysubstance use trend over 6 months. 
Felt well supported by Kelly and Tiffany (Participant 1)

\section{Outreach by Kelly and Tiffany (Participant 2)}

Moreover, the impact of using a community-based approach and peer-to-peer model was mentioned in the data, such as the following quote by a PROMPT participant:

I really feel like I belong somewhere, I do not like to call it a program, it is a group. Program feels like something forced upon you, this is so welcoming, I feel like coming here and I get help. (Participant 3)

Another theme that was present in the data captured the health benefits of smoking cessation. The following quotes speak to the changes in QOL experienced by PROMPT participants, after reducing or quitting tobacco and other substances:

Now that I am smoking less, I did not have to sneak out on my grandkids when I went to play with them over the weekend. Else, I always had to make up a story and sneak out hurriedly to take a few puffs, because the cravings were so bad. I had no cravings this weekend and played for the full fourhours with my grandkids, felt so good. (Participant 4)

My chronic back pain is so much better now that I am smoking only 2-3 cigarettes. (Participant 5)

During the end of the study, many of the participants started to associate smoking with other substance use:

I didn't realize that smoking had such a large effect on my breathing and general health. Now that I think about it everyone who smokes crack or uses [other illicit substances such as heroin, fentanyl, cocaine etc.] also smokes cigarettes. (Participant 6)

Finally, many of the participants reported that free access to 'off-label' personalised NRT helped them in their efforts to reduce or quit smoking tobacco:

The NRT was helpful, especially being able to choose whatever mix I needed to help me kick the habit (Participant 7)

\section{DISCUSSION AND CONCLUSION}

The PROMPT project was a feasibility mixed methods prospective cohort study that describes the detailed psycho-socioeconomic variables associated with tobacco smoking and polysubstance use in the most at-risk marginalised inner city population of Ottawa (Canada). The project demonstrated that a comprehensive programme focused on tobacco dependence management available in community and implemented in true partnership with community (peer) researchers is feasible (>40\% retention rate) and may even produce outcomes beyond tobacco smoking reduction or cessation. In the PROMPT cohort, participants at baseline smoked an average of
20.5 cigarettes per day. However, with time mean cigarette use reduced significantly $(9.3, \mathrm{P}=0.0001)$ in the majority of the participants (see figure 2). Smoking reduction is known to lead to smoking cessation, ${ }^{42}$ and thus a longer duration of support may well have produced a higher percentage of smoking cessation in the study cohort. Cessation was defined as smokers with exhaled $\mathrm{CO} \leq 10 \mathrm{ppm}$ (see figure 2). Moreover, a sizeable number of participants at study-end self-reported a reduction and in some cases cessation of other polysubstance use $(18.8 \%)$ (see figure 3 ). Within opioid use, a self-reported reduction was observed in heroin (6.3\%), fentanyl $(2.6 \%)$ and Oxycontin (3.8\%). Participants that followed up the longest were more likely to report a reduction in cigarette smoking and illicit substance use, in addition to an improvement in overall SES, relative to participants that were lost to follow-up early in the project. Qualitative findings show that PROMPT participants experienced considerable psycho-socio-economic benefits such as better health (weight gain, improved breathing and physical exercise, enrolments in school and drug treatment, etc) and social outcomes (eg, returning to the work force, improved housing, reunification with family, greater community engagement, etc). Overall qualitative findings reveal that the QOL of a third of the participants improved; and that community-based research involving peer-to-peer engagement holds the potential for improving health and meaningfully engaging marginalised communities in health research. It is important to note, however, that while observational research has been documented to be consistent with randomised controlled trials (RCTs) in estimating the magnitude of the effects of treatment ${ }^{434}$ - the outcomes of the PROMPT project will be further investigated in a pragmatic multicentre RCT with homeless (at-risk for homelessness) people who use drugs in Canada and the USA.

It is well known that SES in a society influences one's health and well-being. Groups that have been traditionally disadvantaged, such as inner city populations tend to have high rates of tobacco smoking. ${ }^{3}$ Furthermore, smoking rates have been declining in Canada, the USA and among other high-income countries; however, the decline has been slower or non-existent among low SES groups. Health interventions such as PROMPT tackle social determinants of health that facilitate substance use and poor health. The wide-ranging benefits (eg, return to work, improved social capital, seeking out healthcare, etc) of holistic interventions can contribute considerably to the reduction of disparities in morbidity and mortality in marginalised communities with an estimated economic value of US $\$ 1.02$ trillion. ${ }^{45}$ This is especially important as the findings of the study show that the majority of participants are relatively young (see table 1) and have been smoking for at least 10 years (see table 2), qualifying the majority of PROMPT participants as high risk for chronic disease burden and many years of productive life lost.

In clinical settings, tobacco use is strongly associated with polysubstance use. ${ }^{12}$ The neurobiology of addiction 
demonstrates that tobacco may have the strongest physiological pull and thus may be the most difficult to quit. Addiction research speaks to the entangled nature of tobacco and polysubstance use strengthened by shared neurobiological processes that trigger dopamine release in the reward pathway of the brain creating pleasure and an additive effect that enhances enjoyment and dependence. ${ }^{46}$ Adolescent research and animal studies confirm the 'gateway to illicit drugs' hypothesis that suggests the introduction of tobacco at an early age increases the likelihood of future illicit drug use. ${ }^{47-49}$ Moreover, epidemiological research on addiction reveals better treatment and recovery outcomes for polysubstance users that quit tobacco use in comparison to counterparts that continue to smoke tobacco. ${ }^{50-52}$ The potential for tobacco use reduction and quitting to lead to the reduction and quitting of other polysubstance use (as seen in PROMPT participants) is thus neurobiologically plausible. ${ }^{1}$

Studies in various clinical populations have reported high rates of tobacco use among persons with depression and anxiety. ${ }^{53}$ According to research, current smokers were 2.5 times more likely to have an anxiety disorder; however, if they were former smokers there is no significant difference in the odds of having an anxiety disorder. ${ }^{53}$ As noted in the PROMPT cohort, $30.0 \%$ reported mild anxiety, $18.8 \%$ reported moderate anxiety and $13.8 \%$ reported severe anxiety (see online supplementary table 3). According to Statistics Canada, the lifetime prevalence of GAD in the general population is approximately $5 \%$ in Canada. ${ }^{54}$ Furthermore, the high comorbidity of anxiety and depressive disorders and the high correlation between depressive and anxiety measures is well known. Not surprisingly, our depression measure, the PHQ-8, strongly correlated with the GAD-7 and therefore in the PROMPT cohort we observed that $37.5 \%$ had mild depressive symptoms, $20.0 \%$ had moderate depressive symptoms and $12.5 \%$ and $1.25 \%$ had moderately severe and severe depressive symptoms, respectively (see online supplementary table 3 ) ${ }^{34}$ There is no dearth of literature that documents that both neurobiological and psychosocial factors reinforce the use of nicotine in people with psychiatric illnesses. ${ }^{556}$ For individuals with chronic mental illness, smoking is a major part of their daily routine and is an activity that provides some structure and a sense of routine to a day with few activities. ${ }^{556}$

The PROMPT project used a community-based participatory action approach with meaningful 'patient engagement' with community (peer) researchers that were truly representative of the study's target population. The PROMPT community (peer) researchers were seen as confidants and were able to encourage participants by providing examples of their own struggles and the successes they experienced in their personal journeys to recovery. With complex social determinants of health at play in the PROMPT population, the project's community-based participatory approach allowed PROMPT participants to develop social networks and enhance their knowledge of available community resources and supports. Furthermore, the participants found that the various community capacity building events and activities led by their peers encouraged their continued engagement and provided them additional support, if and when they needed it. According to Davidson $e t$ al, peer support staff are viewed more like friends than non-peer case managers or clinical staff for several reasons, a major one being that they share personal stories with the participants which allows for the development of social relationships. Furthermore, the relationships community (peer) researchers developed with participants was reciprocated as both parties learned from each other and provided support to one another. ${ }^{57}$

Future research and additional programming is required to understand the mechanisms by which interventions such as PROMPT help marginalised hard-to-reach inner city populations. A community-based participatory action research approach, 'by the people, for and with the people', is promising as it provides a novel approach to complex public health issues such as poverty and isolation leading to homelessness, tobacco smoking and polysubstance use. The PROMPT project's patient-centred, personalised, tailored approach to dispensing NRT and developing a quit plan and supports appropriate for active drug users is difficult to replicate in a clinical setting and necessitates a community-based approach. The project's success recruiting, engaging and potentially influencing the health outcomes of a highly vulnerable hard-to-reach population surpassed initial expectations of feasibility and tobacco reduction and cessation. The impact of the project speaks to the need for additional, personalised and holistic community-based peer-led support to reduce health inequities in marginalised communities. ${ }^{58}$ The PROMPT model's holistic and compassionate approach can also be used as part of a strategy addressing the growing opioid use crisis in the USA and Canada. ${ }^{59}$ Additionally, the model holds the potential to be adapted for other complex and chronic health issues such as diabetes and obesity in different populations and in different settings including community-based integrated care.

\section{STUDY LIMITATIONS AND DELIMITATIONS}

A limitation of the project was that it was conducted in one inner city setting. Nonetheless, many of the inner city populations across the USA and Canada have a demographic profile similar to the participant profile in the PROMPT project. Thus, the project can be implemented in similar settings across the USA and Canada. Additionally, a larger study with a greater sample size will need to be conducted to demonstrate an effect on clinical outcomes. Lastly, while the findings are promising, the lack of a control limits the inferences that can be made from the study results. The PROMPT study was a mixed method feasibility study designed to 
lay the foundation for an RCT. A plan is underway to conduct a pragmatic multicentre RCT to examine the impact and potential of the PROMPT model.

Acknowledgements The authors are indebted to all of our PROMPT community researchers, without their trust in the academic research team and dedication towards harm reduction this project would not have been possible. PROMPT participants demonstrated resilience throughout the project; and despite their day-to-day struggles they kept coming for follow-ups, we are so very grateful for your inner strength. The authors thank Dr Peter Selby and his team at the CAMH in Toronto, Canada for their belief in the PROMPT model and support through the STOP programme. The authors are also thankful to the Ottawa chapter of CMHA for providing excellent nurses for our project. The authors also wish to thank local healthcare allies: the Shepherds of Good Hope, Ottawa Inner City Health, Sandy Hill Community Health Centre (CHC), Somerset West CHC, without their in-kind support it would not have been possible to implement the project. The Community Advisory Committee at the Bridge, comprised of Tara, Rick, Ted and Petrina (PROMPT participants) and K Florence (a PROMPT community (peer) researcher), R Boyd (Oasis, Sandy Hill CHC), S Willmott (Somerset CHC), J Haddad (CMHA), K McNaughton (Ottawa Inner City Health Inc.), and S Pakhale (PROMPT lead scientist) meet monthly at the Bridge and guide the mission and vision of the space along with overseeing the smooth functioning of all projects. The authors are indebted to the vision, dedication and passion of the Bridge CAC. The authors are thankful to the Ottawa Hospital, especially Dr Jack Kitts, Dr Jim Worthington, Dr Jeff Turnbull, Dr Mike Tierney, Dr Bill Cameron, Dr lan Graham, Dr Antoine Hakim and the administrative staff for administrative and moral support in maintaining the community space, the Bridge Engagement Centre. The authors thank the EuroQol questionnaire team (EQ-5D-3L) for allowing them to use the questionnaire pro-bono for this project. Last but certainly not least, the authors are grateful to all the reviewers of this manuscript, their feedback was immensely helpful.

Contributors SP, KF, MT contributed to the conception and design of the study. SP, TK, KF, TR, CC, SJ, RB and JH made substantial contributions to the acquisition of the data, data entry or data analysis and data interpretation. SP, TK, CC, KF, TR, SJ, RB, JH, GA and MT were all involved in the drafting of the manuscript or the revisions made to the manuscript. All authors have given final approval of the version of the manuscript submitted for publication, and agree to be accountable for all aspects of the work.

Funding This work was supported by the Champlain Local Health Integration Network; Department of Medicine and the Divisions of Respirology and Cardiology at the Ottawa Hospital, Ottawa, Canada.

Competing interests None declared.

Patient consent Obtained.

Ethics approval Ottawa Health Science Network Research Ethics Board.

Provenance and peer review Not commissioned; externally peer reviewed.

Data sharing statement All available data can be obtained by contacting the corresponding author.

Open Access This is an Open Access article distributed in accordance with the Creative Commons Attribution Non Commercial (CC BY-NC 4.0) license, which permits others to distribute, remix, adapt, build upon this work non-commercially, and license their derivative works on different terms, provided the original work is properly cited and the use is non-commercial. See: http://creativecommons.org/ licenses/by-nc/4.0/

(c) Article author(s) (or their employer(s) unless otherwise stated in the text of the article) 2018. All rights reserved. No commercial use is permitted unless otherwise expressly granted.

\section{REFERENCES}

1. U.S.Department of Health and Human Services. The health consequences of smoking-50 years of progress- a report of the surgeon general. 2014 http://www surgeongeneral gov/library/ reports/50-years-of-progress/exec-summary pdf (cited 8 Sep 2014).

2. Reid JL, Hammond D, Rynard VL, et al. Tobacco use in Canada: patterns and trends, 2014.

3. Hiscock R, Bauld L, Amos A, et al. Socioeconomic status and smoking: a review. Ann N Y Acad Sci 2012;1248:107-23.
4. Reid JL, Hammond D, Boudreau C, et al. Socioeconomic disparities in quit intentions, quit attempts, and smoking abstinence among smokers in four western countries: findings from the International Tobacco Control Four Country Survey. Nicotine Tob Res 2010;12(suppl 1):S20-S33.

5. Blas E, Kurup AS. Equity, social determinants of health and public health programmes: WHO, 2010. http://apps.who.int/iris/bitstream/ 10665/44289/1/9789241563970_eng.pdf

6. Jha $\mathrm{P}$, Peto $\mathrm{R}$, Zatonski W, et al. Social inequalities in male mortality, and in male mortality from smoking: indirect estimation from national death rates in England and Wales, Poland, and North America. Lancet 2006;368:367-70.

7. Kunst A, Giskes K, Mackenbach J. Socio-economic inequalities in smoking in the european union: applying an equity lens to tobacco control policies: for the EU network on interventions to reduce socio-economic inequalities in health. Rotterdam, The Netherlands: Erasmus Medical Center Rotterdam, 2004.

8. Blackman T. Can smoking cessation services be better targeted to tackle health inequalities? Evidence from a cross-sectional study. Health Educ J 2008;67:91-101.

9. Dube SR, Asman K, Malarcher A, et al. Cigarette smoking among adults and trends in smoking cessation - United States, 2008. MMWR Morb Mortal Wkly Rep 2009;58:1227-32.

10. Reid JL, Hammond D, Driezen P. Socio-economic status and smoking in Canada, 1999-2006: has there been any progress on disparities in tobacco use? Can J Public Health 2010;101:73-8.

11. Sharma A, Lewis S, Szatkowski L. Insights into social disparities in smoking prevalence using Mosaic, a novel measure of socioeconomic status: an analysis using a large primary care dataset. BMC Public Health 2010;10:1.

12. Hays LR, Farabee D, Miller W. Caffeine and nicotine use in an addicted population. J Addict Dis 1998;17:47-54.

13. Wielgosz A, Jaffey J, Williams K, et al. Champlain cardiovascular disease prevention network. Atlas of cardiovascular health in the champlain region 2011, 2011.

14. Pakhale S, Kaur T, Florence K, et al. The Ottawa Citizen Engagement and Action Model (OCEAM): a citizen engagement strategy operationalized through the participatory research in Ottawa, management and point-of-care of tobacco (PROMPT) study. Res Involv Engagem 2016;2:1-18.

15. Lazarus L, Shaw A, LeBlanc S, et al. Establishing a communitybased participatory research partnership among people who use drugs in Ottawa: the PROUD cohort study. Harm Reduct $J$ 2014;11:26.

16. Clarke JG, Stein MD, McGarry KA, et al. Interest in smoking cessation among injection drug users. Am J Addict 2001;10:159-66.

17. Stark MJ, Campbell BK. Drug use and cigarette smoking in applicants for drug abuse treatment. J Subst Abuse 1993;5:175-81.

18. Jarvis MJ, Wardle J. Social patterning of individual health behaviours: the case of cigarette smoking, 2005.

19. Eversman MH. Harm reduction in U.S. tobacco control: constructions in textual news media. Int J Drug Policy 2015;26:575-82.

20. McNeill A, Munafò MR. Reducing harm from tobacco use. $J$ Psychopharmacol 2013;27:13-18.

21. Keyser-Marcus L, Vassileva J, Stewart K, et al. Impulsivity and cue reactivity in smokers with comorbid depression and anxiety: Possible implications for smoking cessation treatment strategies. Am J Drug Alcohol Abuse 2017;43:432-41.

22. Bloom EL, Minami H, Brown RA, et al. Quality of life after quitting smoking and initiating aerobic exercise. Psychol Health Med 2017;22:1127-35.

23. Prochaska JJ, Delucchi K, Hall SM. A meta-analysis of smoking cessation interventions with individuals in substance abuse treatment or recovery. J Consult Clin Psychol 2004;72:1144-56.

24. Mamary EM, Bahrs D, Martinez S. Cigarette smoking and the desire to quit among individuals living with HIV. AIDS Patient Care STDS 2002;16:39-42.

25. Zale EL, Dorfman ML, Hooten WM, et al. Tobacco smoking, nicotine dependence, and patterns of prescription opioid misuse: Results from a nationally representative sample. Nicotine Tob Res 2015;17:1096-103.

26. Gomes T. Ottawa must act quickly on opioid crisis. Ontario, Canada: Toronto Star, 2016. https://www.thestar.com/opinion/ commentary/2016/09/06/ottawa-must-act-quickly-on-opioid-crisis. html

27. Gershon L. Five Studies: Understanding America's Opioid Crisis. California: Pacific Standard, 2016.

28. PROMPT quit smoking program helps butt out drug use. Toronto, Canada: CBC News, 2016. http://www.cbc.ca/news/canada/ottawa/ prompt-quit-smoking-drug-program-1.3536743 
29. Heatherton TF, Kozlowski LT, Frecker RC, et al. The fagerström test for nicotine dependence: a revision of the fagerström tolerance questionnaire. Br J Addict 1991;86:1119-27.

30. Bourbeau J, Tan WC, Benedetti A, et al. Canadian Cohort Obstructive Lung Disease (CanCOLD): fulfilling the need for longitudinal observational studies in COPD. COPD 2014;11:125-32.

31. Buist AS, McBurnie MA, Vollmer WM, et al. International variation in the prevalence of COPD (the BOLD Study): a population-based prevalence study. Lancet 2007;370:741-50.

32. Jones PW, Brusselle G, Dal Negro RW, et al. Properties of the COPD assessment test in a cross-sectional European study. Eur Respir $J$ 2011;38:29-35

33. Pickard AS, Wilke C, Jung E, et al. Use of a preference-based measure of health (EQ-5D) in COPD and asthma. Respir Med 2008;102:519-36.

34. Kroenke K, Spitzer RL, Williams JB. The PHQ-9: validity of a brief depression severity measure. J Gen Intern Med 2001;16:606-13.

35. Swendsen JD, Merikangas KR. The comorbidity of depression and substance use disorders. Clin Psychol Rev 2000;20:173-89.

36. Kroenke K, Strine TW, Spitzer RL, et al. The PHQ-8 as a measure of current depression in the general population. $J$ Affect Disord 2009;114:163-73.

37. Ruiz MA, Zamorano E, García-Campayo J, et al. Validity of the GAD-7 scale as an outcome measure of disability in patients with generalized anxiety disorders in primary care. $J$ Affect Disord 2011;128:277-86.

38. van der Zanden BP, Dijkgraaf MG, Blanken P, et al. Validity of the EQ$5 \mathrm{D}$ as a generic health outcome instrument in a heroin-dependent population. Drug Alcohol Depend 2006;82:111-8.

39. Tran BX, Ohinmaa A, Nguyen LT. Quality of life profile and psychometric properties of the EQ-5D-5L in HIV/AIDS patients. Health Qual Life Outcomes 2012;10:132.

40. Belita E, Sidani S. Attrition in smoking cessation intervention studies: a systematic review. Can J Nurs Res 2015:47:21-40.

41. Courtney RJ, Clare P, Boland V, et al. Predictors of retention in a randomised trial of smoking cessation in low-socioeconomic status Australian smokers. Addict Behav 2017;64:13-20.

42. Wennike $\mathrm{P}$, Danielsson $\mathrm{T}$, Landfeldt $\mathrm{B}$, et al. Smoking reduction promotes smoking cessation: results from a double blind, randomized, placebo-controlled trial of nicotine gum with 2-year follow-up. Addiction 2003;98:1395-402.

43. Concato J, Shah N, Horwitz RI, Randomized HRI. Randomized, controlled trials, observational studies, and the hierarchy of research designs. N Engl J Med 2000;342:1887-92.

44. Benson K, Hartz AJ. A comparison of observational studies and randomized, controlled trials. N Engl J Med 2000;342:1878-86.
45. Thornton RL, Glover CM, Cené CW, et al. Evaluating strategies for reducing health disparities by addressing the social determinants of health. Health Aff 2016;35:1416-23.

46. Mendelsohn CP, Wodak Am A. Smoking cessation in people with alcohol and other drug problems. Aust Fam Physician 2016;45:569-73.

47. Reed SC, Izenwasser S. Nicotine produces long-term increases in cocaine reinforcement in adolescent but not adult rats. Brain Res 2017;1654:165-70.

48. McQuown S, Dao J, Belluzzi J, et al. Differential behavioral and neurochemical effects of nicotine treatment in adolescent and adult rats. The FASEB Journal 2008;22:905-3.

49. Corrigall WA. Nicotine self-administration in animals as a dependence model. Nicotine Tob Res 1999;1:11-20.

50. Weinberger AH, Funk AP, Goodwin RD. A review of epidemiologic research on smoking behavior among persons with alcohol and illicit substance use disorders. Prev Med 2016;92:148-59.

51. Lemon SC, Friedmann PD, Stein MD. The impact of smoking cessation on drug abuse treatment outcome. Addict Behav 2003;28:1323-31.

52. Kohn CS, Tsoh JY, Weisner CM. Changes in smoking status among substance abusers: baseline characteristics and abstinence from alcohol and drugs at 12-month follow-up. Drug Alcohol Depend 2003;69:61-71.

53. Degenhardt L, Hall W. The relationship between tobacco use, substance-use disorders and mental health: results from the National Survey of Mental Health and Well-being. Nicotine Tob Res 2001;3:225-34.

54. Statistics Canada: Anxiety Disorders. Canada: Statistics Canada, 2016. http://www.statcan.gc.ca/pub/82-619-m/2012004/sections/ sectionb-eng.htm

55. Ziedonis DM, Kosten TR, Glazer WM, et al. Nicotine dependence and schizophrenia. Psychiatric Services 1994;45:204-6.

56. El-Guebaly N, Cathcart J, Currie S, et al. Smoking cessation approaches for persons with mental illness or addictive disorders. Psychiatr Serv 2002;53:1166-70.

57. Rowe M, Bellamy C, Baranoski M, et al. A peer-support, group intervention to reduce substance use and criminality among persons with severe mental illness. Psychiatr Serv 2007;58:955-61.

58. Wilson SR, Strub P, Buist AS, et al. Shared treatment decision making improves adherence and outcomes in poorly controlled asthma. Am J Respir Crit Care Med 2010;181:566-77.

59. Clarke H, Katz J. No quick fix to society's opioid crisis. Toronto, Canada: Toronto Star, 2016. https://www.thestar.com/opinion/ commentary/2016/09/26/no-quick-fix-to-societys-opioid-crisis. html 